\section{Dietary phenylalanine requirements in infants with hyperphenylalaninaemia}

Sir,

We should like to disagree with the conclusions of D. R. Lines and Marilyn Swanson (Archives, 1973, 48, 648) concerning the dietary requirements of phenylalanine in infants with different forms of hyperphenylalaninaemia.

We define hyperphenylalaninaemia in the same way as they did (serum phenylalanine between $5 \mathrm{mg}$ and 20 $\mathrm{mg} / 100 \mathrm{ml}$ blood on normal milk diet). We have observed that these infants could tolerate a larger amount of phenylalanine while on a restricted diet than that proposed by the authors. In some cases dietary phenylalanine could reach 90 or even $100 \mathrm{ml} / \mathrm{kg}$ per day. These amounts, exceeding those given to typical phenylketonuric individuals, are necessary to maintain a plasma phenylalanine level between 4 and $10 \mathrm{mg} / 100 \mathrm{ml}$ (fluorimetric estimation).

For example, Fig. 1 and 2 illustrate the requirements of three types of infant: a hyperphenylalaninaemic group, a phenylketonuric group with high degree of tolerance, and a phenylketonuric group with low degree of tolerance. These three groups can be clearly differentiated. In the hyperphenylalaninaemic group the high tolerance observed at first $(100 \mathrm{mg} / \mathrm{kg}$ per day or more) can decrease to about $70 \mathrm{mg} / \mathrm{kg}$ per day in the following months, or it can remain unchanged. In the 'typical' phenylketonuric group with a low degree of tolerance, the patients, around the age of 6 months, can only tolerate a restricted amount of phenylalanine of $42 \pm 5 \mathrm{mg} / \mathrm{kg}$ per day. In this phenylketonuric group there are a few infants with plasma phenylalanine levels above $20 \mathrm{mg} / 100 \mathrm{ml}$ with phenylpyruvic and $o$-hydroxyphenylacetic acids in the urine, whose requirements for phenylalanine were higher than the $65 \pm 15 \mathrm{mg} / \mathrm{kg}$ per day at the age of 1 and 2 months, and around $50 \pm 5$ $\mathrm{mg} / \mathrm{kg}$ per day at the age of 6 months and after 1 year.

Our experience based on 25 cases followed for 3 years make us think that the views of Lines and Swanson are unduly strict, and could induce a deficiency state from the use of so restricted a diet. The apparent disagreement between these authors and ourselves may be due to the fact that our definition of hyperphenylalaninaemia, though identical, may be being applied to a different group of patients, since in classifying an infant within the hyperphenylalaninaemic group we insist on the absence of urinary metabolites (phenylpyruvic and o-hydroxyphenylacetic acids).

DENISE MESMACQUE-CABY, JEAN-PIERRE FARRIAUX, GUY FONTAINE Laboratoire de Recherche et Clinique Pédiatrique, Cité Hospitalière, 59000 Lille, France.

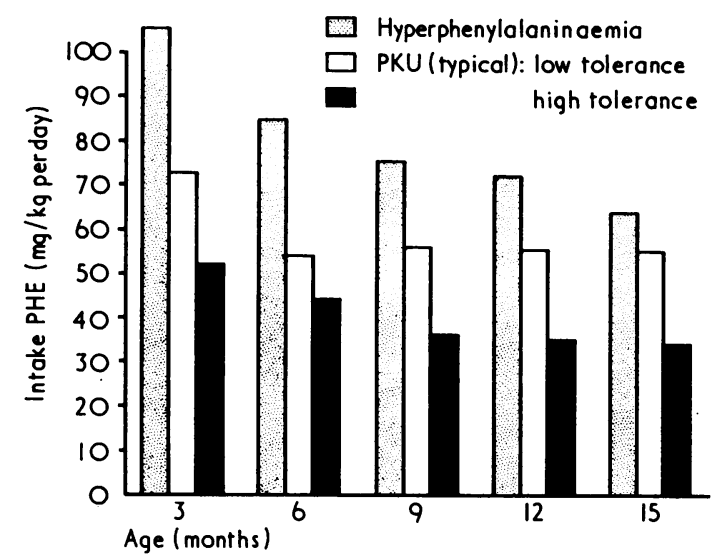

Fig. 1.-Phenylalanine intake in infants with hyperphenylalaninaemia and typical PKU (low or high tolerance) during the first 15 months of life.

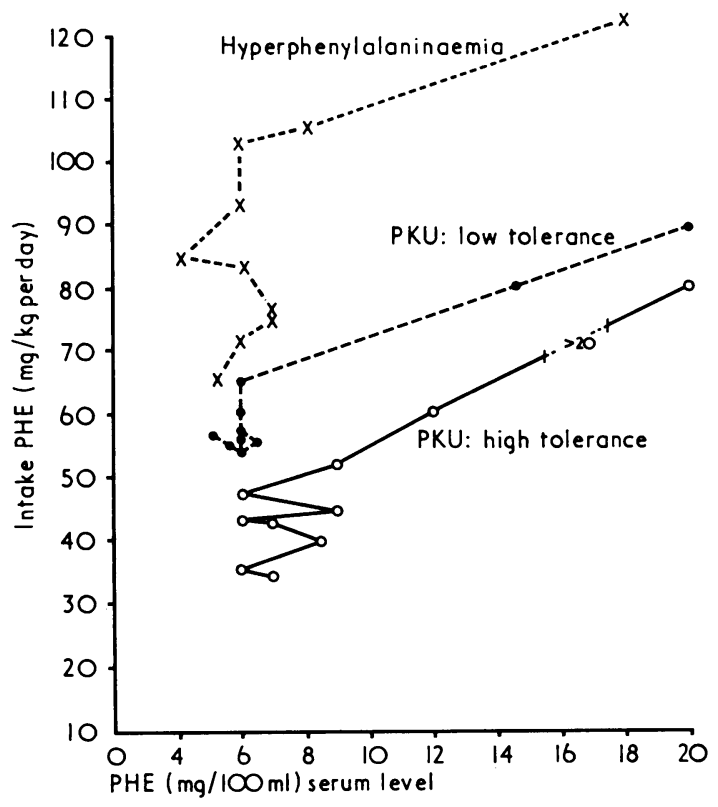

FIG. 2.-Dietary requirements of phenylalanine in infants with different forms of hyperphenylalaninaemia. 